\begin{tabular}{||l|l|l|}
\hline \multicolumn{2}{|c|}{ PublisherInfo } \\
\hline \hline PublisherName & $:$ & BioMed Central \\
\hline \hline PublisherLocation & $:$ & London \\
\hline \hline PublisherImprintName & $:$ & BioMed Central \\
\hline \hline
\end{tabular}

\title{
Type V collagen induces apoptosis of 8701-BC breast cancer cells and enhances m-calpain expression
}

\begin{tabular}{||l|l|l||}
\hline \multicolumn{2}{|c||}{ ArticleInfo } \\
\hline \hline ArticleID & $:$ & 60 \\
\hline \hline ArticleDOI & $:$ & $10.1186 /$ bcr60 \\
\hline \hline ArticleCitationID & $:$ & E008 \\
\hline \hline ArticleSequenceNumber & $:$ & 14 \\
\hline \hline ArticleCategory & $:$ & Non-peer-reviewed research \\
\hline \hline ArticleFirstPage & $:$ & 1 \\
\hline \hline ArticleLastPage & $:$ & \\
\hline \hline & & RegistrationDate : 2000-1-12 \\
\hline ArticleHistory & $:$ & Received $\quad$ 2000-1-12 \\
\hline \hline ArticleContext & $:$ & OnlineDate $\quad$ 2000-3-21 \\
\hline \hline ArticleGrants & $:$ & The Author(s)2000 \\
\hline \hline
\end{tabular}


Ida Pucci-Minafra, ${ }^{\text {Aff1 Aff2 }}$

Fax: +39091424732

Cintia Carella, ${ }^{\text {Aff1 }}$

Rosalia Cirincione, ${ }^{\text {Aff1 }}$

Silvana Chimenti, ${ }^{\text {Aff1 }}$

Salvatore Minafra, ${ }^{\text {Aff1 Aff2 }}$

Fax: +39 091424903

Claudio Luparello, ${ }^{\text {Aff1 }}$

Affl Dipartimento di Biologia Cellulare e dello Sviluppo, Università, Viale delle Scienze, Palermo, Italy

Aff2 Centro di Oncobiologia Sperimentale, Viale delle Scienze, Palermo, Italy

\section{Abstract}

\section{Introduction}

We previously reported that ductal infiltrating carcinomas (DIC) of the human breast display profound modifications of the stromal architecture, associated with anomalous collagen composition. The major alterations observed in the interstitial collagen were an abnormal ratio between type I and type III collagens, the appearence of an onco-foetal form of collagen (OF/LB) and a relative increase of type $\mathrm{V}$ collagen content. Biological assays performed by culturing a DIC-derived cell line (8701-BC) onto type $\mathrm{V}$ collagen substrate demonstrated that the latter was able to restrain cell growth and to inhibit cell motility and invasion "in vitro", differently from what found with other collagen species tested.

\section{Aims}

To search for molecular mechanisms underlying the observed inhibitory effect of collagen type $\mathrm{V}$ on breast cancer cells. As a reference model, we used culture substrates prepared with type IV collagen, which represents the physiological substrate for cells of epithelial origin.

\section{Methods}

Apoptosis was studied by both fluorescence microscopical analyses of cell viability and DNA fragmentation assays in preparations of 8701-BC cells grown onto either type $\mathrm{V}$ and type IV collagen. Differences in gene expression following cell adhesion onto the two substrates were analyzed by a "differential display" PCR (DD-PCR) technique and Western blot. 


\section{Results}

In this paper we demonstrate that the inhibitory effect exerted by type $\mathrm{V}$ collagen is consistently associated with the switching-on of a death program by a significant proportion of the cell culture, concomitant with the formation of cohesive cell islands displaying a progressive decrease of cell spreading. DD-PCR and Western blot assays demonstrated a consistent association of type $\mathrm{V}$ collagen-promoted apoptosis with the up-regulation of the large subunit of m-calpain (L-mC) at both mRNA and protein level. Cell exposure to calpain inibitor I decreased the amount of DNA fragmentation by $30 \%$.

\section{Discussion}

The present data substantiate our previous postulates that in cases of breast DIC the zonal increase of type V collagen contribute to the assembly of a "non-permissive" micro-environment for tumor cells, antagonist to other local permissive substrates. It is therefore conceivable that the spatiotemporal derangement of stromal components may actively modulate neoplastic cell behavior and metastatic propensity, thus contributing to the selection and development of more or less malignant tumor phenotypes.

\section{Keywords}

apoptosis, breast cancer, calpain, collagen type V, differential display.

\section{INTRODUCTION}

The interdynamic space-temporal interactions of given cells with their extracellular matrix (ECM) are known to drive morphogenesis during development and to maintain the normal tissue architecture and functions in adult organs. Cellular behaviors that are modulated by (or associated to) cell-matrix interactions include growth [1,2], differentiation [3,4,5], apoptosis [6], motility [7,8,9], signal transduction and gene expression $[10,11,12,13,14]$, to quote among the major effects. Local disruption of ECM after pathologic events, may result in selective reprogrammed cell behavior, through a cascade of signals difficult to predict a priori.

Some previous data obtained in one of our laboratories have shown that in cases of the ductal infiltrating carcinoma (DIC), a highly malignant tumor of the human breast, the stromal ECM undergoes to extensive regional remodelling with enhanced deposition of collagen components, mostly modified with respect to the normal counterpart $[15,16]$. The major aspects were the over-deposition of type $\mathrm{V}$ collagen normally expressed at very low levels in adult tissues, and the appearence an onco-foetal form of interstitial collagen $(\mathrm{OF} / \mathrm{LB})[17,18,19]$. Biological assays performed with a neoplastic cell line 
(8701-BC), isolated from a primary DIC [20], demonstrated that different collagen substrates were able to promote distinct behaviors of the cell population: in particular, the onco-foetal collagen enhanced cell proliferation and migration and promoted invasivity both "in vitro" and "in vivo", whilst type V collagen exerted an antagonistic effect, restraining both cell growth and "in vitro" invasivity [2,8,21,22,23,24].

In consideration of the potentially-relevant implications of restrictive forces on tumor progression, we set out experiments to understand how this inhibitory effect of collagen type $\mathrm{V}$ is exerted on cancer cells. As a reference model, we used culture substrates prepared with type IV collagen, which represents the physiological substrate for cells of epithelial origin. First, to address the question whether type V collagen was able to promote programmed cell death, we performed fluorescence microscopical analyses of cell viability and DNA fragmentation assays, both by gel electrophoresis and centrifugal sedimentation. Secondly, we investigated the possibility of some transcriptional specificity induced by type V collagen substrates on 8701-BC cells, by applying the technique of the "differential display"polymerase-chain-reaction (DD-PCR) described by Sokolov and Prockop [25] which allows the identification of cDNas from differentially-expressed genes by analysis of their internal sequences after reverse transcription with random hexamers and amplification in the presence of arbitrary primers.

By this experimental approach, here we demonstrate that type $\mathrm{V}$ collagen is able to promote apoptosis in a large fraction of 8701-BC cells, and that the apoptotic process is associated with a marked increase of expression and production of the large subunit of m-calpain (L-mC; EC 3.4.22.17), a neutral Ca ${ }^{++}$ dependent non-lysosomal enzyme belonging to the cystein protease family $([26,27,28]$ for reviews).

\section{MATERIALS AND METHODS}

\section{Cell cultures}

8701-BC cells were routinely cultured in RPMI 1640 medium supplemented with $10 \%$ foetal calf serum and antibiotics. Collagen type IV and V were purchased from Sigma (St.Louis, MO/USA). Collagens were dissolved in $0.5 \mathrm{M}$ acetic acid, sterilized with chloroform as already reported in Luparello et al. [2], plated in $25 \mathrm{~cm}^{2}$ flasks at the concentration of $10 \mu \mathrm{g} / \mathrm{cm}^{2}$ for $48 \mathrm{~h}$ and exhaustively neutralized with PBS just before cell culturing. 8701-BC cells, detached with $0.1 \%$ EDTA, were plated in substrate-coated flasks at the concentration of $3.5 \times 10^{4} / \mathrm{cm}^{2}$ in serum-free conditions and allowed to grow for $48 \mathrm{~h}$.

\section{Fluorescence microscopy}

A mixture of acridine orange and ethidium bromide (both purchased from Sigma and dissolved at 2 $\mu \mathrm{g} / \mathrm{ml}$ of PBS) was added to the culture medium of unfixed 8701-BC cells grown for $48 \mathrm{~h}$ onto either 
type IV or type V collagen substrate, and the cells viewed immediately under either FITC (for acridine orange) or TRITC (for ethidium bromide) fluorescence [29] and photographed.

\section{DNA fragmentation assays}

The occurrence of DNA fragmentation was evaluated electrophoretically as described by Navarro et al. [30] with slight modifications, and its extent checked by centrifugal sedimentation as reported by Duke and Cohen [31].

For the electrophoretic assay, 8701-BC cells were plated onto either type IV collagen- or type V collagen-coated 6-well dishes, at the concentration of $6 \times 10^{5}$ (for type IV collagen) and $1.2 \times 10^{6}$ cells/ well (for type $\mathrm{V}$ collagen) and grown for $48 \mathrm{~h}$ in serum-free medium. At the end of the incubation, cells were scraped from the plates, lysed in $100 \mu \mathrm{l}$ of $45 \mathrm{mM}$ Tris-borate, $\mathrm{pH} 8$, containing $0.25 \%$ Nonidet P-40 substitute and $10 \mathrm{mM}$ EDTA, and treated for $1 \mathrm{~h}$ at $50^{\circ} \mathrm{C}$ with $1 \mathrm{mg}$ RNase A/ml (Fluka, Buchs/ $\mathrm{CH}$ ) and then for $1 \mathrm{~h}$ at $50^{\circ} \mathrm{C}$ with $1 \mathrm{mg}$ Proteinase $\mathrm{K} / \mathrm{ml}$ (Fluka). Samples were mixed with loading buffer (10 mM EDTA, pH 8, plus $0.25 \%$ bromophenol blue, $40 \%$ sucrose and $1 \%$ low melting pointagarose) and, in order to improve band resolution, they were submitted to voltage gradient gel electrophoresis (VGGE; [32,33]) in ethidium bromide-containing 1.2\% agarose gel with TAE buffer for $5 \mathrm{~h}$ at $60 \mathrm{~V}$.

For the quantitative evaluation of DNA fragmentation, 8701-BC cells were plated at the concentration of $1 \times 10^{5}$ cells/well onto either type IV collagen- or type V collagen-coated 4-well dishes in serum-free conditions and allowed to adhere onto the substrates for $24 \mathrm{~h}$. Subsequently, a set of cells was incubated with $2 \mu \mathrm{Ci} / \mathrm{ml}$ [methyl- $\left.{ }^{3} \mathrm{H}\right]$ thymidine $\left(\left[{ }^{3} \mathrm{H}\right] \mathrm{TdR}\right)$, for $18 \mathrm{~h}$, whilst in parallel preparations, the $18 \mathrm{~h}$ treatment with $\left[{ }^{3} \mathrm{H}\right] \mathrm{TdR}$ was performed after additonal $24 \mathrm{~h}$ (i.e. at $48 \mathrm{~h}$ from seeding). Cells were then exhaustively washed with RPMI 1640 medium pre-warmed to $37^{\circ} \mathrm{C}$ and lysed with TTE solution (10 $\mathrm{mM}$ Tris-HCl, $\mathrm{pH} 7.4$, containing 0.2\% Triton X-100 and 1 mM EDTA); the fragmented DNA was then separated from intact chromatin by centrifugation. The radioactivity present in both the supernatant and the pellet, the latter resuspended in $1 \%$ SDS, was evaluated by liquid scintillation counting. Percent DNA fragmentation was calculated as [(c.p.m in the supernatant)/(c.p.m. in the supernatant plus c.p.m. in the pellet)]. Data are presented as mean \pm s.e.m. of quadruplicate experiments. A Student's t-test was used and $p<0.05$ was taken as the minimal level of statistical significance of the differences between samples and controls. the dna fragmentation assay following calpain inhibition followed essentially the same protocol with the exception that either $20 \mu \mathrm{m}$ calpain inhibitor i (N-acetyl-Leu-Leu-norleucinal purchased by Boehringer; [34]) in DMSO or DMSO vector only were added to cell plating medium.

\section{Messenger RNA extraction and reverse transcription}


Isolation of polyA ${ }^{+}$mRNA from monolayers of 8701-BC cells grown for $48 \mathrm{~h}$ onto either type IV or $\mathrm{V}$ collagen substrate was carried out with oligo-dT25tailed magnetic beads using the mRNA DIRECT kit purchased from Dynal (Oslo/N). The protocol for the latter included the preparation of crude cell lysate, annealing of polyadenylated mRNA to the beads, washing of the suspension and elution of purified transcripts. Samples of 0.1-0.5 $\mu \mathrm{g}$ of mRNA were submitted to cDNA synthesis in the presence of random 6-mer primers, using the SuperScript Preamplification System (Gibco), according to manufacturer's instructions.

\section{Differential Display-Polymerase Chain Reaction (DD-PCR) and Sequencing}

For differential expression analysis, DD-PCR experiments were performed using the arbitrary 10-mer primers designed by Sokolov and Prockop [25], i.e. BS52 (5'-CAAGCGAGGT-3'), BS54 (5'AACGCGCAAC-3'), BS55 (5'-GTGGAAGCGT-3') and BS57 (5'-GGAAGCAGCT-3'), in combinations of two. The PCR amplification was carried out using 25 pmoles of each of two primers, 1-2 $\mu$ of the cDNA template and 3.6 U of AmpliTaq DNA Polymerase, Stoffel fragment (Perkin Elmer, USA), in 50 $\mu \mathrm{l}$ of the appropriate reaction mixture. The thermal cycle used was a denaturation step of $94.5^{\circ} \mathrm{C}$ for 3 min., followed by 45 cycles of $94.5^{\circ} \mathrm{C}$ for $1 \mathrm{~min}$., $34^{\circ} \mathrm{C}$ for $1 \mathrm{~min} ., 72^{\circ} \mathrm{C}$ for $1 \mathrm{~min}$. and a final extension of the product for $10 \mathrm{~min}$. at $72^{\circ} \mathrm{C}$. PCR products were analysed by $6 \%$ non-denaturing polyacrylamide gel electrophoresis, followed by silver staining [35,36]. PBR322 plasmid digested with Hinfl was used as size marker $(154,220 / 221,298,344,396,506,517$ and 1,631 bp fragments). The cDNA fragment of interest was excised from the gel and subjected to several repetitions of amplification and electrophoresis until purity. Direct dideoxy-sequencing of both strands of the PCR product, purified with the High Pure PCR Product Purification Kit (Boehringer), was carried out with Sequenase (Amersham, UK) in the presence of either BS52 or BS57 primer and ${ }^{33}$ P-labelled dATP. DNA sequence similarity was searched with the BLAST algorithm [37] available on-line at http:| Wwww.ncbi.nlm.nih.gov.

\section{Semi-quantitative PCR}

Non-competitive semi-quantitative PCR was performed at low cycle number [38] using $50 \mu \mathrm{M}$ of the primers for L-mC (accession nr. M23254), i.e. 5'-CAAAAACTTCTTCCTGACGAATCG-3' (sense) and 5'-CCAGACCTGTCAACGTCGATT-3' (antisense), designed with the Primer Selection software available on-line at http://http: \lalces.med.umn.edu, and specific for a $512 \mathrm{bp}$ sequence from bases 1477-1989 of the L-mC coding sequence [39]. Cycle profile was $94^{\circ} \mathrm{C}$ for $2 \mathrm{~min}$., followed by 18 cycles of $94^{\circ} \mathrm{C}$ for $30 \mathrm{sec} ., 47^{\circ} \mathrm{C}$ for $45 \mathrm{sec} ., 72^{\circ} \mathrm{C}$ for $1 \mathrm{~min}(5 \mathrm{~min}$. during the last cycle). Primewax (Biometra) was added for "hot start". GAPDH was amplified in parallel as described by Southby et al. [40]. PCR products and size marker (PBR322 plasmid/Hinfl) were analysed by 6\% PAGE and visualized at $254 \mathrm{~nm}$ transillumination after staining with SYBR Green I. SigmaGel 1.0 software was utilized for the evaluation of pixel intensity of the fluorescent bands. A diagnostic restriction test was designed using the WWW tacg program, available at http: \|hornet.bio.uci.edu; according to the data 
obtained, the amplification product of L-mC cDNA, purified by High Pure PCR Product Purification Kit (Boehringer), was digested with excess PstI enzyme and the digest analyzed by PAGE as described.

\section{Protein extraction and Western blot}

Cells were plated in collagen-coated flasks in serum-free conditions and allowed to grow for $48 \mathrm{~h}$, as already reported. Cell lysis was performed with $20 \mathrm{mM}$ Tris-HCl, $\mathrm{pH}$ 7.4, containing 2\% SDS, $5 \mathrm{mM}$ EGTA, $5 \mathrm{mM}$ EDTA, $0.5 \mathrm{mM}$ PMSF, $5 \mu \mathrm{g}$ leupeptin/ml and $10 \mu \mathrm{g}$ aprotinin $/ \mathrm{ml}$; total proteins were extracted and TCA precipitated according to Wang et al. [41]. Measured aliquots of the extracted proteins were subjected to SDS-PAGE (7.5\% acrylamide). Western-blot was performed with anti-L-mC antibody from rabbit $(1: 1,000$; Swant, Bellinzona/CH), and the reaction revealed by horseradish peroxidase-conjugated anti-rabbit $\operatorname{IgG}(1 \mathrm{U} / \mathrm{ml}$; Boehringer $)$ and staining with diaminobenzidine according to [34]. The evaluation of the pixel intensity of the bands was done by automated scanning using SigmaGel 1.0 software. Beta-actin was immunostained in parallel to confirm the loading of the proper amount of material.

\section{RESULTS}

\section{Apoptosis of 8701-BC cells cultured onto type V collagen}

For the microscopical investigation of cell viability we performed double-fluorescence assays, after staining unfixed cells with acridine orange and ethidium bromide, being the latter unable to permeate the intact membrane of live cells and thereby representing a marker for morphological detection of cell death. As shown in fig. 1, panel A1-3 (FITC filter for acridine orange), cells plated onto type IV collagen reached confluence $48 \mathrm{~h}$ after seeding, acquiring a spread morphology and organizing themselves in a uniform and continuous monolayer covering the total culture area. Conversely, cells plated onto type V collagen (fig. 1, panel B1-3) grew as cohesive islands of different size, with increasing cell-cell contacts and progressive decreasing of cell extensions. Shifting to the TRITC filter, the same fields were observed for ethidium bromide staining: as shown in fig. 1, panel A 4-6, cell plated onto type IV collagen exhibited a very limited uptake of ethidium bromide, while cells attached onto type V collagen (fig. 1, panel B 4-6) displayed a more marked level of cell death. 
Figure 1 Fluorescence microscopical analysis of 8701-BC cells grown for $48 \mathrm{~h}$ onto either type IV (panel A) or type V collagen substrates (panel B) and stained with acridine orange (1-3) and ethidium bromide (4-6). Microscopical magnification 40 X.
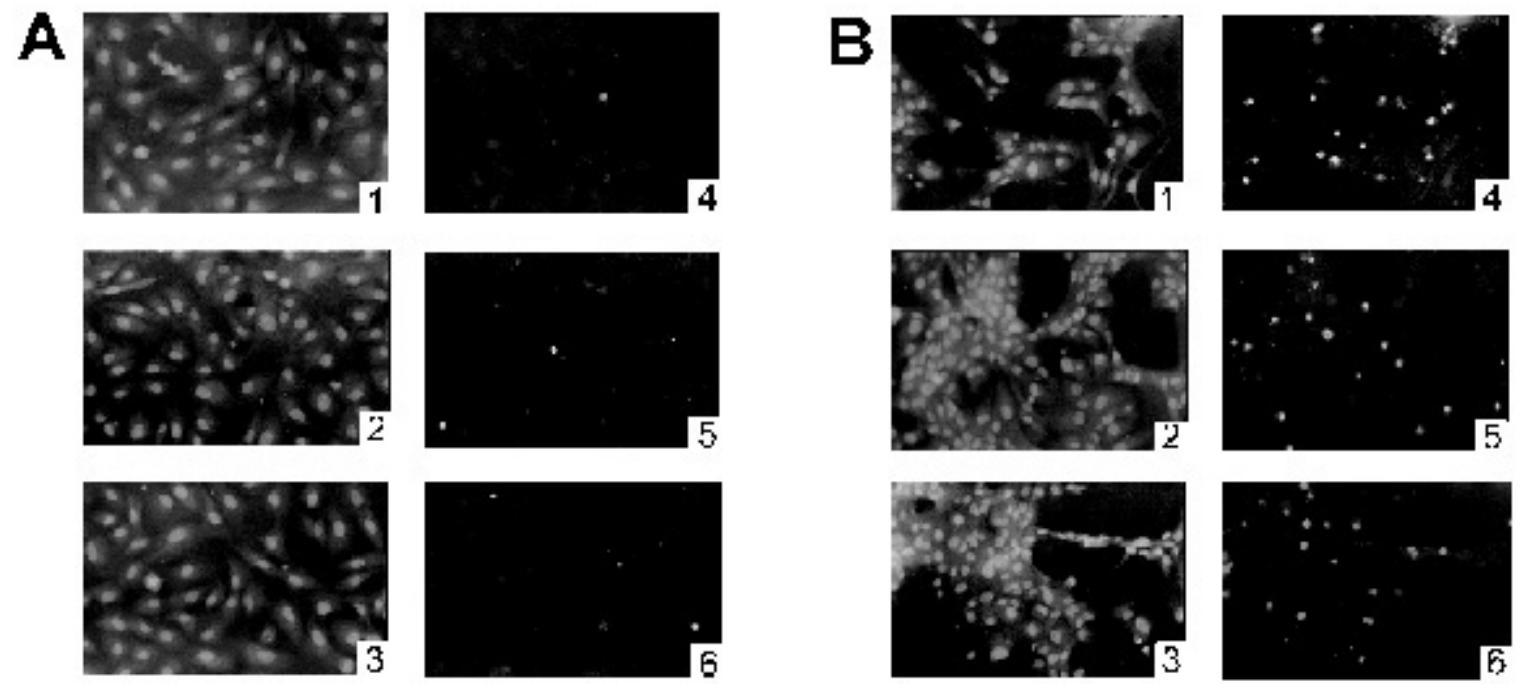

In light of these morphological observations, we then performed an electrophoretic assay to check the status of the DNA extracted from cells cultured onto type IV and type V collagens. The DNA ladder, indicative of internucleosomal DNA fragmentation, was apparent after $48 \mathrm{~h}$ of growth onto type $\mathrm{V}$ collagen substrate, whilst only intact high-molecular weight DNA was present in cells grown onto type IV collagen substrate (fig. 2). The amount of fragmented DNA in cells cultured onto either substrates was therefore quantitated by centrifugal sedimentation after labelling with tritiated thymidine, at 48 and $72 \mathrm{~h}$ after plating (fig. 3). As expected, cells cultured onto type V collagen substrate, had a much higher level of DNA fragmentation, both at 48 and $72 \mathrm{~h}$ after seeding $(86.1 \pm 1.1 \%$ and $87.25 \pm 0.35 \%$, respectively) compared to that of cells cultured onto type IV collagen $(16 \pm 0.01 \%$ and $13.25 \pm 1.25 \%$, respectively). 
Figure 2 VGGE of the DNA isolated from 8701-BC cells grown for $48 \mathrm{~h}$ onto either type IV or type $\mathrm{V}$ collagen substrates. Agarose 1.2\%, ethidium bromide stain

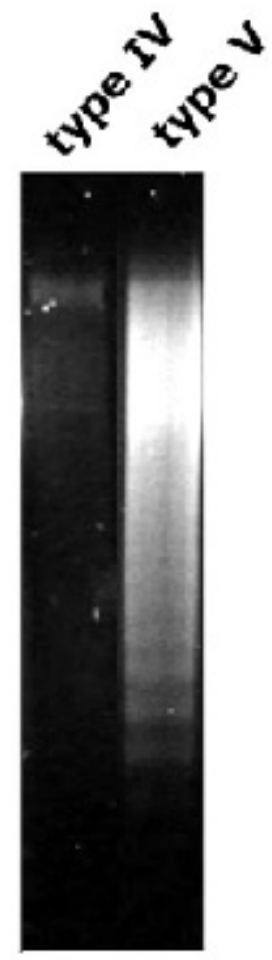


Figure 3 Extent of DNA fragmentation in 8701-BC cells after 48 and $72 \mathrm{~h}$ from seeding onto either type IV or type V collagen substrates. Vertical bars indicate the s.e.m. of quadruplicate experiments. $* p<0.05$ (type $\mathrm{V}$ versus type IV collagen)

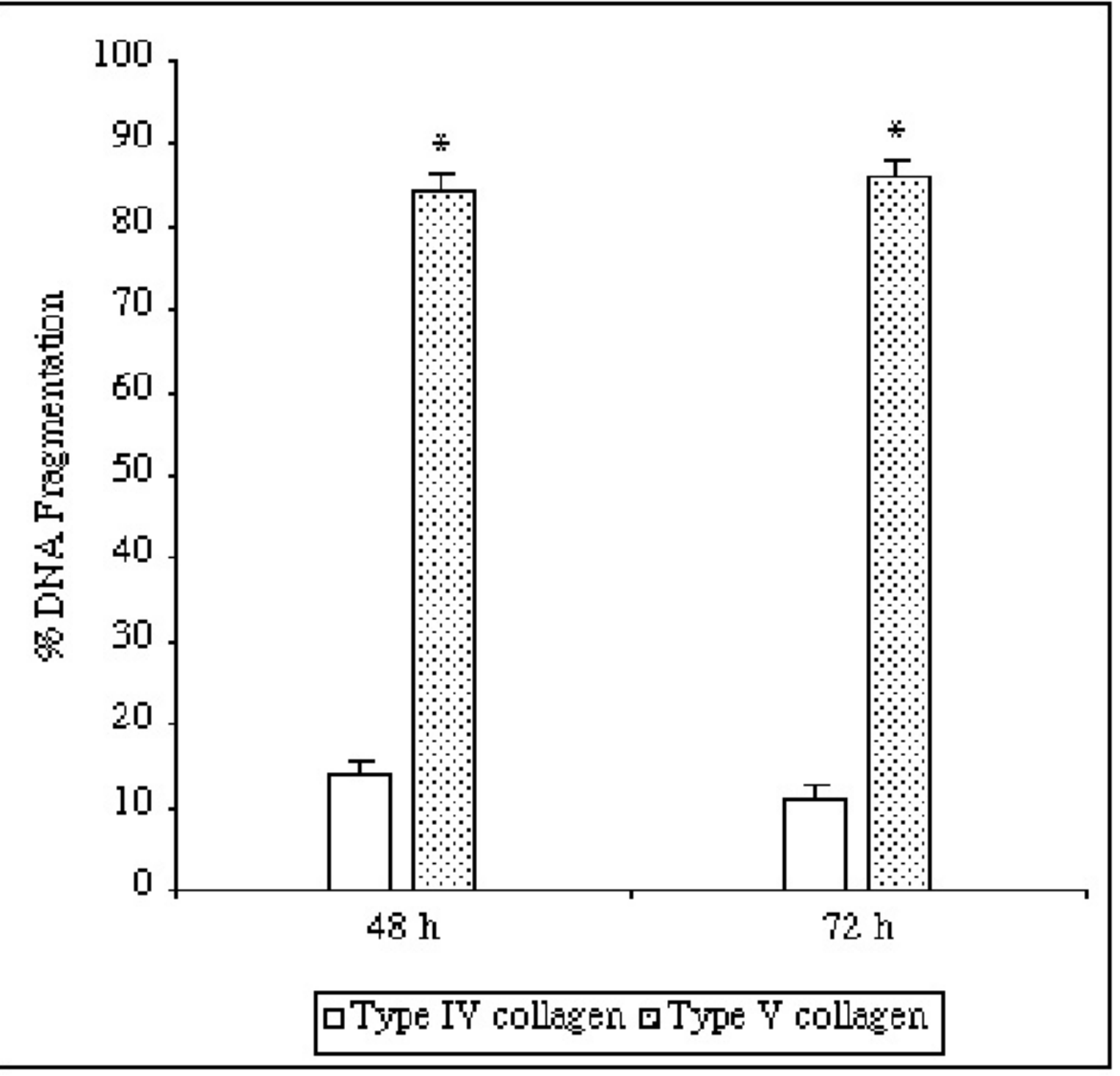

\section{Up-regulation of L-mC in 8701-BC cells cultured onto type $\mathrm{V}$ collagen}

In order to search for putative molecular markers linked to the apoptotic switch induced by type $\mathrm{V}$ collagen, we submitted cDNA preparations, obtained from 8701-BC cells grown onto the two different substrates, to DD-PCR as described. Only one out of the four combinations of arbitrary primers utilized (i.e. BS52-BS57) gave an amplification band of approx. 165 bp selectively present in the cDNA preparation of cells cultured onto type V collagen (fig. 4). The $165 \mathrm{bp}$-cDNA fragment was purified by excision from the gel and several cycles of PCR and electrophoresis and submitted to direct dideoxysequencing of both strands; homology was found in the EMBL and GeneBank DNA data bases between 
the partial sequence obtained and that of region 2148-2225 of the coding sequence for $L-m C$ (accession number M23254) as deposited by Imajoh et al. [39].

Figure 4 DD-PCR of cDNA preparations from 8701-BC cells grown onto either type IV or type V collagen substrates amplified in the presence of primers BS52 and BS57. The arrow points to a band of about 165 bp selectively present in type V collagen-derived preparations. Sequencing PAGE 6\%, silver stain.

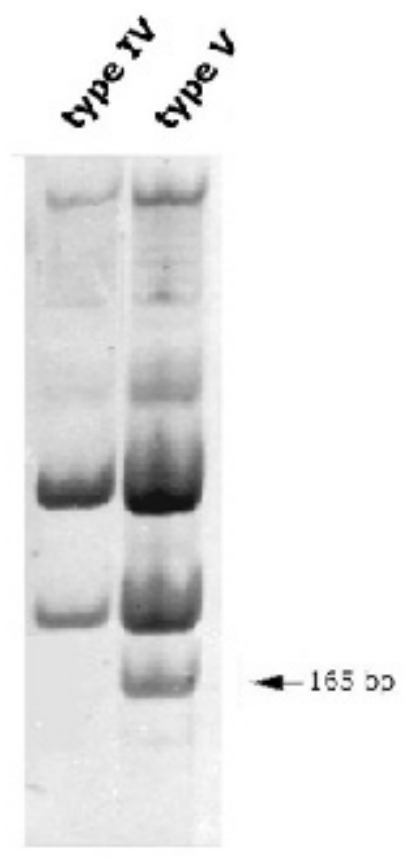

To check the differential expression of $L-m C$ under alternative experimental conditions enhancing the stringency and sensitivity of the test, a new set of cDNA samples from 8701-BC cells was subjected to PCR analysis in the presence of two primers specific for L-mC mRNA, designed by the "Primer selection" software available on-line. As shown in fig. 5A, the PCR amplification gave a product which displayed a size (512 bp) identical to that expected theoretically; moreover, to confirm its identity, the amplification product was submitted to diagnostic restriction analysis with PstI, successfully releasing the two fragments of 196 and 316 bp predicted. For semi-quantitative evaluation, the various cDNA preparations from 8701-BC cells were submitted to PCR analysis keeping cycle number low to maintain the linear relationship between input RNA and final product [38] and amplifying the "housekeeping" gene GAPDH in parallel as a control for starting material. The little amount of PCR product generated was revealed by the highly-sensitive SYBR Green I stain. As shown in fig. 5B, when PCR amplification was performed in the presence of the specific primers, the signal for L-mC (normalized to that of GAPDH) was at least four times higher in cells plated onto type V collagen than in cells grown onto type IV collagen. 
Figure 5 A) PCR amplification of the 512 bp product of L-mC cDNA (1), and diagnostic restriction analysis of the same yielding the expected 316 and $196 \mathrm{bp}$ fragments after digestion with PstI endonuclease (2). M) Size marker PBR322 plasmid/Hinfl. B) "Low cycle number"-PCR amplification of cDNA preparations from 8701-BC cells grown onto either type IV or type V collagen substrates in the presence of primers specific for L-mC and GAPDH cDNA fragments. PAGE 6\%, SYBR Green I stain.

A

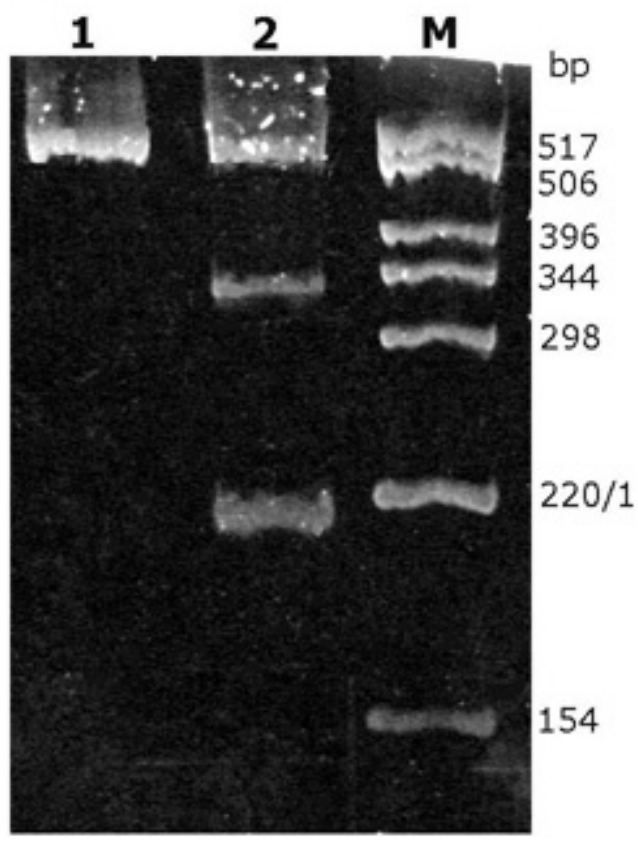

B
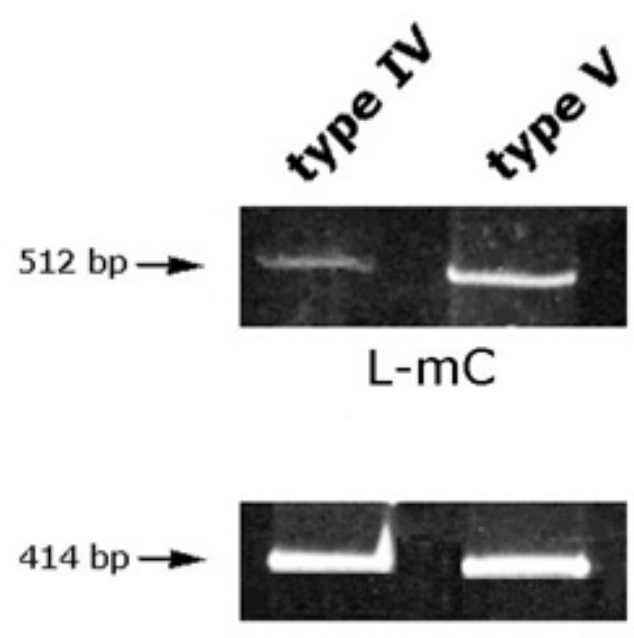

GAPDH

We then checked whether the observed increase of $L-m C$ gene expression found was correlated to the presence of an enhanced amount of L-mC protein product. For this purpose, equal amounts of total protein extracts from cells cultured onto the two different collagen substrates were submitted to Western blot in the presence of an antibody specific for L-mC; the results obtained (fig. 6) showed a consistently stronger staining of L-mC in preparations of cells grown on type $\mathrm{V}$ collagen, than in those obtained from cells grown onto type IV collagen. Beta-actin was used as a control for gel loading. 
Figure 6 Western blot analysis of L-mC content and control $\beta$-actin in lysates of 8701-BC cells grown onto the different collagen substrates.

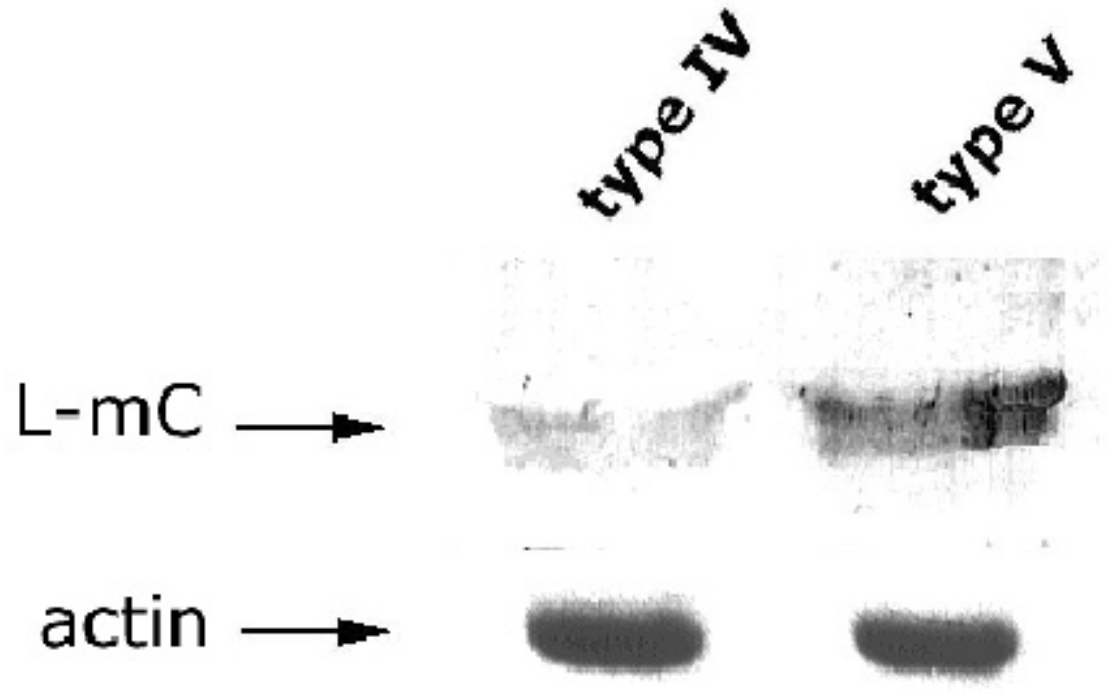

\section{Inhibition of calpain and reduction of the extent of DNA fragmentation in 8701-BC cells grown onto type $\mathrm{V}$ collagen}

To check whether calpain played a role in the apoptosis induced on 8701-BC cells by type V collagen, a cell-permeant inhibitor of calpain, calpain inhibitor I [42], was used at the concentration recommended by Squier et al. [34].

As shown in fig. 7, the addition of the calpain inhibitor to the medium of cells seeded on type $\mathrm{V}$ collagen-coated dishes resulted in an about 59\% DNA fragmentation, both after 48 and $72 \mathrm{~h}$ from seeding; this represents approximately a 30\% reduction of the amount of fragmented DNA with respect to untreated cells. Conversely, the calpain inhibitor exerted a "paradoxical" effect ( $48 \pm 8 \%$ of DNA fragmentation, i.e. about $+30 \%$ versus untreated cells) only after $72 \mathrm{~h}$ when supplemented to the medium of cells seeded on type IV collagen-coated dishes. DMSO vector only was used in parallel control tests and it appeared not to modify significantly the extent of DNA fragmentation found in serum-free medium supplemented cultures. 
Figure 7 Effect of calpain inhibitor I on DNA fragmentation in 8701-BC cells cultured onto either type IV or V collagen substrates for 48 and $72 \mathrm{~h}$. Vertical bars indicate the s.e.m. of quadruplicate experiments. ${ }^{*} p<0.05$ (treated versus control samples).

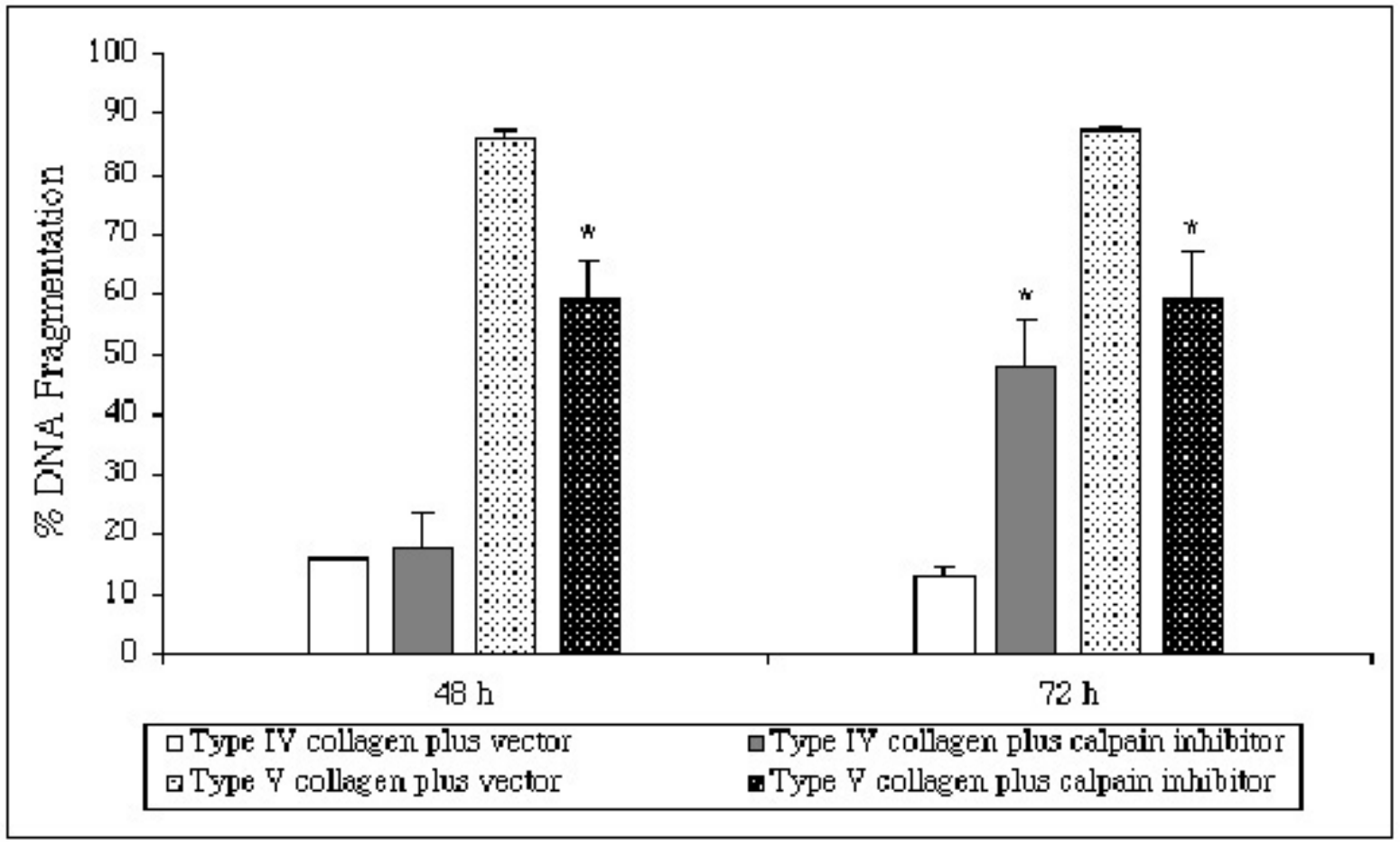

\section{DISCUSSION}

Type V collagen, a minor component of the multigenic collagen family, was originally detected in foetal membranes [43] and subsequently found, as a minor fraction of the total collagen, in several embryonic and adult tissues, where it occurs in a pericellular localization [44,45]. However, although the molecular and structural characteristics of type V collagen have been thoroughly investigated (see [46]), its biological role remains uncertain.

Some authors demonstrated that in mature tissues type V collagen molecules are buried within the major collagen fibrils $[47,48]$ and therefore, in normal situations the epitopes for cell adhesion are not readily available to cells. Conversely, during tissue remodelling or in tumor invasion, enhanced deposition of collagen type $\mathrm{V}$ has been observed [19,49,50], and it is conceivable that it could become transiently available for cell adhesion, driving some specific cellular functions. However, the data so far available show that the cellular responses driven by this collagen appear inconsistent, suggesting differences among the model systems examined (e.g. tissues and cell types). For example, cell adhesionpromoting activity has been observed for normal smooth muscle cells [51,52], chinese hamster ovary cells [53], and some tumor cells [54]; conversely, anti-adhesive and anti-proliferative effects have been observed on endothelial cells [55,56,57], vascular smooth muscle cells [58] and some epithelial cells [59], besides the 8701-BC cancer cell line [2].

Present results confirm our previous observations on the "in vitro" inhibitory effect of type V collagen on cell proliferation, and offer an explanation of the biological mechanisms involved. Indeed, the 
decrease of the expected growth rate in a given cell population may be due to two possible responses: a slow-down of the duplication rates or an increase rate of programmed cell death. The data presented here clearly support the second hypothesis. As it is known, apoptosis is a cell death program that produces specific morphological and biochemical modification, including loss of adherence to the substrate, cell shrinking in volume and chromatin condensation and separation into discrete masses, that produce a ladder-like pattern when the fragmented DNA is electrophoresed through agarose gels [60]. All the above-mentioned phenomenoma have been shown to occur in a large percentage of cells cultured onto type V collagen substrate.

Concerning the cell pathways involved in the apoptotic process, the knowledge is still fragmentary, but it is known that it invariably requires the activation of proteolytic cascades that are not yet welldefined. Cystein proteases, a family of non-lysosomal neutral proteases whose major members are calpain and caspases, have been considered as important intermediates in this cascade [61]. Some authors suggested that the proteolytic cascade is initiated after upstream caspase activation [62], others that calpains and the proteasome (a multicatalytic enzymatic complex) function synergistically downstream of caspases [63]. Concerning calpain substrates, cytoskeletal components (e.g. spectrin, fodrin, actin), membrane-linked proteins (e.g. $\mathrm{Ca}^{++}$pump) and nuclear/cytosolic proteins [28], including cyclin D1 [64], have been recognised in a number of "in vitro" assays. Villa et al. [65] have suggested that the correlation between calpain-driven apoptosis and cytoskeleton might be ascribed to the efficacy of calpain to release DNase I from actin microfilaments, thus becoming more available for DNA fragmentation. Interestingly, as a support to this hypothesis in our model system, previous fluorescence microscopical analysis of actin in 8701-BC cells plated on type V collagen revealed the lack of a wellorganized microfilament array [2], which was instead prominently present in cells cultured onto other collagen substrates [8,21].

Due to the importance of the apoptotic process in tissue homeostasis and in cancer biology and therapy, in the last few years a multiplicity of substances has been investigated as possible inducer/ blockers of apoptosis (e.g. [66]), but, to our knowledge, this is the first documented indication that an endogenous tissue component, like type $\mathrm{V}$ collagen, is able to promote apoptosis in cancer cells. The expression of other components required for the apoptotic activation following 8701-BC adhesion onto type $\mathrm{V}$ collagen is currently under investigation

The present data substantiate our previous postulates that in cases of breast DIC the zonal increase of type $\mathrm{V}$ collagen contribute to the assembly of a "non-permissive" micro-environment for tumor cells, antagonist to other local permissive substrates $[2,8,21,23,24]$. It is therefore conceivable that the spatiotemporal derangement of stromal components may actively modulate neoplastic cell behavior and metastatic propensity, thus contributing to the selection and development of more or less malignant tumor phenotypes. 


\section{Acknowldgements}

This work was suppported by A.I.R.C. and M.U.R.S.T. (R.S. ex 60\% and 40\%)

\section{References}

1. Chou JL, Shen ZX, Stolfi RL, Martin DS, Waxman S: Effects of extracellular matrix on the growth and casein gene expression of primary mouse mammary tumor cells in vitro . Cancer Res. 1984, 49: 5371-5376.

2. Luparello C, Schillaci R, Pucci-Minafra I, Minafra S: Adhesion, growth and cytoskeletal characteristics of 8701-BC breast carcinoma cells cultured in the presence of type V collagen. Eur J Cancer. 1990, 26: 231-240.

3. Adams JC, Watt FM: Regulation of development and differentiation by the extracellular matrix. Development. 1993, 117: 1183-1198.

4. Hay ED: Extracellular matrix alters epithelial differentiation. Curr Opin Cell. Biol. 1993, 5: 1029-1035.

5. Streuli CH: Extracellular matrix and gene expression in mammary epithelium. Semin Cell Biol. 1993, 4: 203-212.

6. Boudreau N, Werb Z, Bissell MJ: Suppression of apoptosis by basement membrane requires threedimensional tissue organization and withdrawal from the cell cycle. Proc Natl Acad Sci. USA. 1996, 93: 3509-3513.

7. Klemke R, Cai S, Giannini AL, Gallagher PJ, de Lanerolle P, Cheresh DA: Regulation of cell motility by mitogen-activated protein kinase. J Cell Biol. 1997, 137: 481-492.

8. Luparello C, Sheterline P, Pucci-Minafra I, Minafra S: A comparison of spreading and motility behaviour of 8701-BC breast carcinoma cells on type I, I-trimer and type V collagen substrates. J Cell Sci. 1991, 100: 179-185.

9. Zetter BR, Brightman SE: Cell motility and the extracellular matrix. Curr Opin Cell Biol. 1990, 2: $850-856$.

10. Juliano RL, Haskill S: Signal transduction from the extracellular matrix. J Cell Biol. 1993, 120: 577-586.

11. Minafra S, Giambelluca C, Andriolo M, Pucci-Minafra I: Cell-cell and cell-collagen interactions influence gelatinase production by human breast carcinoma cell line 8701-BC. Int J Cancer. 1995, 62: $1-7$. 
12. Roskelley CD, Srebrow A, Bissell MJ: A hierarchy of ECM-mediated signalling regulates tissuespecific gene expression. Curr Opin Cell Biol. 1995, 7: 736-747.

13. Danen E, Lafrenie R, Miyamoto S, Yamada K: Integrin signaling: cytoskeletal complexes, MAP kinase activation, and regulation of gene expression. Cell Adhes Commun. 1998, 6: 217-224.

14. Lelièvre $\mathrm{S}$, Weaver $\mathrm{V}$, Nickerson $\mathrm{J}$, et al: Tissue phenotype depends on reciprocal interactions between the extracellular matrix and the structural organization of the nucleus. Proc Natl Acad Sci USA. 1998, 95: 14711-14716.

15. Minafra S, Pucci-Minafra I, Tomasino RM, Sciarrino S: Collagen composition in the ductal infiltrating carcinoma of human breast. Cell Biol Int Rep. 1984, 8: 79-85.

16. Pucci-Minafra I, Luparello C, Sciarrino S, Tomasino RM, Minafra S: Quantitative determination of collagen types present in the ductal Infiltrating carcinoma of human mammary gland. Cell Biol Int Rep. 1985, 9: 291-296.

17. Pucci-Minafra I, Luparello C, Andriolo M, Basiricò L, Aquino A, Minafra S: A new form of tumor and foetal collagen with laminin-binding property. Biochemistry. 1993, 32: 7421-7427.

18. Pucci-Minafra I, Andriolo M, Basiricò L, et al: Onco-fetal/laminin-binding collagen from colon carcinoma: detection of new sequences. Biochem Biophys Res Commun. 1995, 207: 852-859. 10.1006/ bbrc.1995.1264.

19. Luparello C, Rizzo CP, Schillaci R, Pucci-Minafra I: Fractionation of type V collagen from carcinomatous and dysplasic breast in the presence of alkaline potassium chloride. Analyt Biochem. 1988, 169: 26-32.

20. Minafra S, Morello V, Glorioso F, et al: A new cell line (8701-BC) from primary ductal infiltrating carcinoma of human breast. Br J Cancer. 1989, 60: 185-192.

21. Schillaci R, Luparello C, Minafra S: Type I and I-trimer collagens as substrates for breast carcinoma cells in culture. Effect on growth rate, morphological appearence and actin organization. Eur J Cell Biol. 1989, 48: 135-141.

22. Pucci-Minafra I , Luparello C: Type V/type I collagen interactions "in vitro" and growth-inhibitory effect of hybrid substrates on 8701-BC carcinoma cells. J Submicrosc Cytol Pathol. 1991, 23: 67-74.

23. Luparello C: Adhesion to type $\mathrm{V}$ collagen and cloning efficiency in agar of 8701-BC breast cancer cells. Eur J Cancer. 1994, 30A: 1400-1401.

24. Pucci-Minafra I, Luparello C, Aquino A, et al: OF/LB collagen promotes chemoinvasion of breast cancer cells and directes epithelial cell migration into granulation tissue of experimental dermal wounds. Int J Oncol. 1995, 6: 1015-1020.

25. Sokolov BP, Prockop DJ: A rapid and simple PCR-based method for isolation of cDNAs from differentially expressed genes. Nucl Acid Res. 1994, 19: 4009-4015. 
26. Johnson GVW, Guttmann RP: Calpains: intact and active?. Bioessays. 1997, 19: 1011-1018.

27. Carafoli E, Molinari M: Calpain: a protease in search of a function?. Biochem Biophys Res Commun. 1998, 247: 193-203. 10.1006/bbrc.1998.8378.

28. Ono Y, Sorimachi H, Suzuki K: Structure and physiology of calpain, an enigmatic protease. Biochem Biophys Res Commun. 1998, 245: 289-294. 10.1006/bbrc.1998.8085.

29. Edwards SN, Tolkovsky : Characterization of apoptosis in cultured rat sympathetic neurons after nerve growth factor withdrawal. J Cell Biol. 1994, 124: 537-546.

30. Navarro JN, Olmo N, Lòpez-Conejo MT, Lizarbe MA: Differentiation of BCS-TC2 human colon adenocarcinoma cells by sodium butyrate: increase in 5'-nucleotidase activity. Eur J Clin Invest. 1997, 27: $620-628$.

31. Duke RC, Cohen JJ: Morphological and biochemical assays of apoptosis. In Current Protocols in Immunology. Edited by Coogan JE, Kruisbeek AM, Margulies DH, Shevach EM, Strober W. New York: Green Publishing and Wiley-Interscience. 1992, 3.17: 1-3.

32. Barbieri R, Duro G, Izzo V: Enhanced hybridization labelling signals in Southern blotted DNAs fractionated with voltage gradient gel electrophoresis. Electrophoresis. 1998, 19: 643-645.

33. Asaro MR, Izzo V, Barbieri R: Modified apparatus for voltage gradient gel electrophoresis. J Chromatogr. 1999,

34. Squier MKT, Miller ACK, Malkinson AM, Cohen JJ: Calpain activation in apoptosis. J Cell Physiol. 1994, 159: 229-237.

35. Caetano-Anollés G, Bassam BJ, Gresshoff PM: Primer-template interactions during DNA amplification fingerprinting with single arbitrary oligonucleotides. Mol Gen Genet. 1992, 235: 157-165.

36. Doss RP: Differential display without radioactivity - A modified procedure. BioTechniques. 1996, 21: 408-412.

37. Altschul SF, Gish W, Miller W, Myers EW, Lipman DJ: Basic local alignment search tool. J Mol Biol. 1990, 215: 403-410. 10.1006/jmbi.1990.9999.

38. Gause WC, Adamovicz J: The use of the PCR to quantitate gene expression. PCR Meth Appl. 1994, 3: S123-S135.

39. Imajoh S, Aoki K, Ohno S, et al: Molecular cloning of the cDNA for the large subunit of the high$\mathrm{Ca}^{++}$-requiring form of human $\mathrm{Ca}^{++}$-activated neutral protease. Biochemistry. 1988, 27: 8122-8128.

40. Southby J, O'Keefe LM, Martin TJ, Gillespie MT: Alternative promoter usage and mRNA splicing pathways for parathyroid hormone-related protein in normal tissues and tumours. Br J Cancer. 1995, 72: 702-707. 
41. Wang KKW, Posner A, Hajimohammadreza I: Total protein extraction from cultured cells for use in electrophoresis and western blotting. BioTechniques. 1996, 20: 662-668.

42. Sasaki T, Kishi M, Saito M, et al: Inhibitory effect of di- and tripeptidyl aldehydes on calpains and calpastatins. J Enzyme Inhib. 1990, 3: 195-201.

43. Burgeson RE, El Adli FA, Kaitila II, Hollister DW: Fetal membrane collagens: identification of two new collagen $\alpha$ chains. Proc Natl Acad Sci USA. 1976, 73: 2579-2583.

44. Gay S, Rhodes RK, Gay RE, Miller EJ: Collagen molecules comprised of $\alpha_{1}$ (V)-chains (B-chains): an apparent localization in the exocytoskeleton. Collagen Rel Res. 1981, 1: 53-58.

45. Modesti A, Kalebic T, Scarpa S, et al: Type V collagen in human amnion is a $12 \mathrm{~nm}$-fibrillar component of the pericellular interstitium. Eur J Cell Bio. 1984, 35: 246-255.

46. Fichard A, Kleman JP, Ruggiero F: Another look at collagen V and XI molecules. Matrix Biol. 1994, 14: 515-531.

47. von Der Mark K, Ocalan M: Immunofluorescent localization of type V collagen in the chick embryo with monoclonal antibodies. Collagen Rel Res. 1982, 2: 541-555.

48. Linsenmayer TF, Gibney E, Igoe F, et al: Type V collagen: molecular structure and fibrillar organization of the chicken $\alpha\left(1(\mathrm{~V}) \mathrm{NH}_{2}\right.$-terminal domain, a putative regulator of corneal fibrillogenesis. J Cell Biol. 1993, 121: 1181-1189.

49. Barsky S, Rao C, Grotendorst G, Liotta L: Increased content of type V collagen in desmoplasia of human breast carcinoma. Am J Pathol. 1982, 108: 276-283.

50. Marian B, Danner MW: Skin tumor promotion is associated with increased type V collagen content in the dermis. Carcinogenesis. 1987, 8: 151-154.

51. Grotendorst GR, Seppä HE, Kleinman HK, Martin GR: Attachment of smooth muscle cells to collagen and their migration toward platelet-derived growth factor. Proc Natl Acad Sci USA. 1981, 78: 3669-3672.

52. Leushner JR, Haust MD: Glycoproteins on the surface of smooth muscle cells involved in their interaction with type V collagen. Can J Biochem Cell Biol. 1985, 63: 1176-1182.

53. LeBaron RG, Höök A, Esko JD, Gay S, Höök M: Binding of heparan sulfate to type V collagen. A mechanism of cell-substrate adhesion. . J Biol Chem. 1989, 264: 7950-7956.

54. Ruggiero F, Champliaud MF, Garrone R, Aumailley M: Interactions between cells and collagen V molecules or single chains involve distinct mechanisms. Exp Cell Res. 1994, 210: 215-223. 10.1006/ excr.1994.1032.

55. Fukuda K, Koshihara Y, Oda H, Ohyama M, Ooyama T: Type V collagen selectively inhibits human endothelial cell proliferation. Biochem Biophys Res Commun. 1988, 151: 1060-1068. 
56. Madri JA, Williams SK: Capillary endothelial cell cultures: phenotypic modulation by matrix components. J Cell Biol. 1983, 97: 153-165.

57. Ziats N, Anderson JM: Human vascular endothelial cell attachment and growth inhibition by type V collagen. J Vasc Surg. 1993, 17: 710-718.

58. Underwood PA, Bean PA, Whitelock JM: Inhibition of endothelial cell adhesion and proliferation by extracellular matrix from vascular smooth muscle cells: role of type V collagen. Atherosclerosis. 1998, 141: 141-152. 10.1016/S0021-9150(98)00164-6.

59. Parekh T, Wang X, Makri-Werzen DM, Greenspan DS, Newman MJ: Type V collagen is an epithelial cell cycle inhibitor that is induced by and mimics the effects of transforming growth factor $\beta 1$. Cell Growth Differ. 1998, 9: 423-433.

60. Martin SJ, Green DR, Cotter TG: Dicing with death: dissecting the components of the apoptosis machinery. Trends Biochem Sci. 1994, 19: 26-30.

61. Kohli V, Madden JF, Bentley RC, Clavien PA: Calpain mediates ischemic injury of the liver through modulation of apoptosis and necrosis. Gastroenterology. 1999, 116: 168-78.

62. Waterhouse NJ, Finucane DM, Green DR, et al: Calpain activation is upstream of caspases in radiation-induced apoptosis. Cell Death Differ. 1998, 5: 1051-1061. 10.1038/sj/cdd/4400425.

63. Knepper NB, Savill J, Brown SB: Constitutive apoptosis in human neutrophils requires synergy between calpains and the proteasome downstream of caspases. J Biol Chem. 1998, 273: 30530-30536.

64. Choi YH, Lee SJ, Nguyen P, et al: Regulation of cyclin D1 by calpain protease. J Biol Chem. 1997, 272: $28479-28484$.

65. Villa PG, Henzel WJ, Sensenbrenner M, Henderson CE, Pettmann B: Calpain inhibitors, but not caspase inhibitors, prevent actin proteolysis and DNA fragmentation during apoptosis. J Cell Sci. 1998, 111: 713-722.

66. Yu W, Simmons-Menchaca M, Gapor A, Sanders BG, Kline K: Induction of apoptosis in human breast cancer cells by tocopherols and tocotrienols. Nutrition Cancer. 1999, 33: 26-32.

This PDF file was created after publication. 